\title{
PREPARATION OF MELT SPUN ELECTROCONDUCTIVE FINE FIBRES CONTAINING CARBON NANOTUBES
}

\author{
Mohammad Mirjalili*, Loghman Karimi ${ }^{2}$ \\ 1Department of Textile Engineering, Yazd Branch, Islamic Azad University, Yazd, Iran \\ ${ }^{2}$ Young Researchers and Elites Club, Science and Research Branch, Islamic Azad University, Tehran, Iran \\ Corresponding author. Tel.: +98 3518231849; fax: +98 3518202126 . \\ E-mail address: dr.mirjalili@iauyazd.ac.ir, drmir_textile@yahoo.com
}

\begin{abstract}
:
Preparation of electroconductive fine fibres containing carbon nanotubes (CNTs) by melt spinning was the main goal of the present study. In this regard, the influence of the main operating parameters such as type of polymer used (polyester, polypropylene and polyamide), type and concentration of the CNTs on conductivity, and mechanical and thermal properties of the melt spun fibres was studied. The conductivity of melt spun fibres was measured based on the method developed by Morton and Hearl. The morphologies of the CNTs-polymer composite fibres were studied by scanning electron microscopy. Thermal behaviours and mechanical properties of the CNTs-polymer composite fibres were investigated using differential scanning calorimetry and tearing tester, respectively. The results reveal that using CNTs had tangible effect on electrical, thermal and mechanical properties of the melt spun fibres. Also, polyamide had a better dispersion of CNTs and correspondingly lower surface resistivity.
\end{abstract}

\section{Keywords:}

fine fibre, conductive fibre, carbon nanotubes, melt spinning

\section{Introduction}

Electrical conductive textiles have received considerable attention due to their possible applications in the areas of electromagnetic shielding, chemical sensors and heating fabrics [1]. The term 'conductive textiles' is used for a broad range of products with widely differing specific (surface) conductivity [2]. For smart and interactive textiles applications, one can choose different methods to prepare electro-conductive polymeric fibres, using an inherently conductive polymer (ICP) or blending an insulating polymer with conductive particles (carbon black, carbon nanotubes (CNTs) or ICPs) and then spinning fibres using melt spinning, wet spinning process or by coating a textile fibre with conductive materials [3-6]. Among the conductive fillers, CNTs have attracted interest because they can improve a number of properties when integrated within the polymeric matrix. CNTs are allotropes of carbon, which can be assorted to four groups according to their wall number: single-wall CNTs (SWCNTs), double-wall CNTs, triple-wall CNTs and multi-wall CNTs (MWCNTs) [7]. CNTs have particular properties such as excellent adsorption [8], high flexibility, low mass density $[9,10]$, electrical conductivity, high strength, elastic modulus, electromagnetic interference shield [11], thermal properties and if they disperse in polymers, they play an important role in the composite properties especially mechanical strength [12-14]. Recently, many researchers have shown great interest in CNTs and their incorporation into polypropylene [15, 16], poly(methyl methacrylate) [17], polycarbonate [18,19], polyimide [20], polyamide [21], poly(ethylene terephthalate) [22], polyurethane [23] and shape memory polyurethane [24] polymer matrices for the formation of fibres.
In this study, polymer/CNTs composite fine fibres were prepared by melt spinning. The electrical, thermal and mechanical properties of the melt spun fibres were examined and reported.

\section{Experimental section}

\section{$\underline{\text { Materials }}$}

Commercially available polyester (PES), polyamide 66 (PA) and polypropylene (PP) chips were obtained from Tondgooyan Co. (Iran). The specifications of used polymers are presented in Table 1. MWCNTs with $95 \%$ purity and outer diameters in the range of $10-20 \mathrm{~nm}$, and SWCNTs with $95 \%$ purity and outer diameters in the range of 5-10 nm were employed from NANOSAV Co. (Iran).

\section{Fabrication of polymer/CNTs composite fibres by melt spinning}

Melt mixing of the granular polymer (dried overnight at $80^{\circ} \mathrm{C}$ ) and the powdery CNTs (dried overnight at $120^{\circ} \mathrm{C}$ ) was done in a twin-screw microcompounder (DSM Xplore, the Netherlands). Polymer and CNTs were alternatively added to the microcompounder. Melt mixing was performed at $250^{\circ} \mathrm{C}$ with a mixing speed of $80 \mathrm{rpm}$ for $14 \mathrm{~min}$. Different blend combinations were prepared: PP/MWCNTs, PES/MWCNTs, PA/MWCNTs, PP/SWCNTs, PES/SWCNTs and PA/SWCNTs. The concentration of CNTs was chosen between 0.25 and $0.75 \mathrm{wt} \%$. A $0.5-\mathrm{mm}$ spinneret was attached to the outlet of the microcompounder to make the fibre monofilaments. As-spun 
Table 1. Specifications of polymers used.

\begin{tabular}{|c|c|c|c|c|}
\hline Chips type & Density $\left(\mathbf{g} / \mathbf{c m}^{3}\right)$ & $\mathbf{T}_{\mathbf{m}}\left({ }^{\circ} \mathbf{C}\right)$ & $\left.\mathbf{T}_{\mathbf{g}} \mathbf{(}^{\circ} \mathbf{C}\right)$ & Specific heat $(\mathbf{J} / \mathbf{k g ~} \mathbf{K})$ \\
\hline PA & 1.14 & $215-220$ & $90-95$ & 1900 \\
\hline PES & $1.35-1.38$ & $255-265$ & $80-110$ & 1100 \\
\hline PP & 0.91 & $165-173$ & $75-80$ & 1700 \\
\hline
\end{tabular}

fibres were collected directly after the spinneret on a rotating take-up roll.

\section{Morphology analysis}

The filament surface morphology was studied with a scanning electron microscopy (SEM, LEO Electron Microscopy Ltd, Cambridge, UK). The fibre surfaces were also analysed by optical stereomicroscopy equipped with CCD camera.

\section{Conductivity of the melt spun fibres}

Resistance melt-spun fibre bundles of 16 fibres were measured with UNTI-T Digital Multimeter, based on the method developed by Morton and Hearl [25].

\section{Differential scanning calorimetry analysis}

The role of CNTs on the crystallization of the pure polymers was investigated by differential scanning calorimetry (DSC) analysis using a SCINCO STA S-1500 simultaneous thermal analyser. The temperature was raised from $40^{\circ} \mathrm{C}$ to decomposition of polymers at a heating rate of $10^{\circ} \mathrm{C} / \mathrm{min}$. The specimen weight in the air was $0.003 \mathrm{~g}$. The enthalpy of the fabricated fibres from $60^{\circ} \mathrm{C}$ to $150^{\circ} \mathrm{C}$ in $(\mathrm{J} / \mathrm{g})$ was obtained using the analysis software associated with the DSC analyser.

\section{Mechanical strength characterization}

The mechanical strength of the melt spun fibres was investigated using a tearing tester machine (INSTRON 3365) on the bundle of fibres. The weight of the bundle of fibres was measured by a mass balance and held fixed between 0.05 and $0.06 \mathrm{~g}$. The length of the bundle was fixed at $2.00 \mathrm{~cm}$.

\section{Results and discussion}

\section{Effect of the MWCNTs concentration on conductivity}

In the first step to optimize the melt-spinning conditions, the effect of MWCNTs concentration (0.25, 0.5 and $0.75 \mathrm{wt} \%$ ) was studied on the conductivity of fibres. Table 2 and Figure 1 exhibit the fibre conductivity test results and the comparative diagram of various polymers, respectively. The results acquired indicate that fibres surface resistance was decreased by increasing MWCNTs amount up to $0.5 \mathrm{wt} \%$, and then slightly increased. It is to be noted that by increasing the amount of CNTs in a polymer matrix, the melt spinning capability of the fibres decreased.

\section{Influence of polymer type on conductivity}

The effect of polymer type (polyester, polypropylene and polyamide) was investigated on the conductivity. These polymers have been selected due to the melt-spinning capability and high consumption in the textile industry. The obtained results reveal that the type of polymer used for producing conductive fibres by melt-spinning has a significant impact on conductivity of the resulting fibres (Table 2). It is observed that the lowest surface resistance and therefore highest conductivity were related to PA fibres containing $0.5 \mathrm{wt} \% \mathrm{CNTs}$, which is due to the better spinning capability of the PA polymer by melt spinning.

\section{Effect of CNTs type on conductivity}

In this step, the effect of CNTs type (single-wall and multi-wall) was investigated on the conductivity of composite fibres. For this purpose, samples containing optimum amount of CNTs (SWCNTs or MWCNTs) was spun. As can be seen in Table 3, composites containing SWCNTs have lower resistance than those containing MWCNTs, which unequivocally confirms the existing assumptions about the properties of the SWCNTs compared with MWCNTs.

\section{Morphology of conductive fine fibre}

The SEM images of the fibre surface are shown in Figure 2. The SEM images of composite fibre show evidence for small globules of CNTs on the surface. The fibres surface was also observed by optical stereomicroscopy equipped with CCD camera. Figure 3 shows the diameter of the fibres. The fibres

Table 2. The measurement results of specific resistance of the fibre by Morton and Hearl method.

\begin{tabular}{|c|c|}
\hline Sample & Rs (M $\mathbf{2})$ \\
\hline$P P+0.25 w t \%$ MWCNTs & 122.2 \\
\hline$P P+0.5 w t \%$ MWCNTs & 101.3 \\
\hline$P P+0.75 w t \%$ MWCNTs & 50 \\
\hline PES + $0.25 w t \%$ MWCNTs & 183.3 \\
\hline PES + 0.5 wt $\%$ MWCNTs & 137.5 \\
\hline PES + 0.75 wt $\%$ MWCNTs & 220 \\
\hline$P A+0.25 w t \%$ MWCNTs & 200 \\
\hline$P A+0.5 w t \%$ MWCNTs & 73.33 \\
\hline PA + $0.75 w t \%$ MWCNTs & 91.6 \\
\hline
\end{tabular}




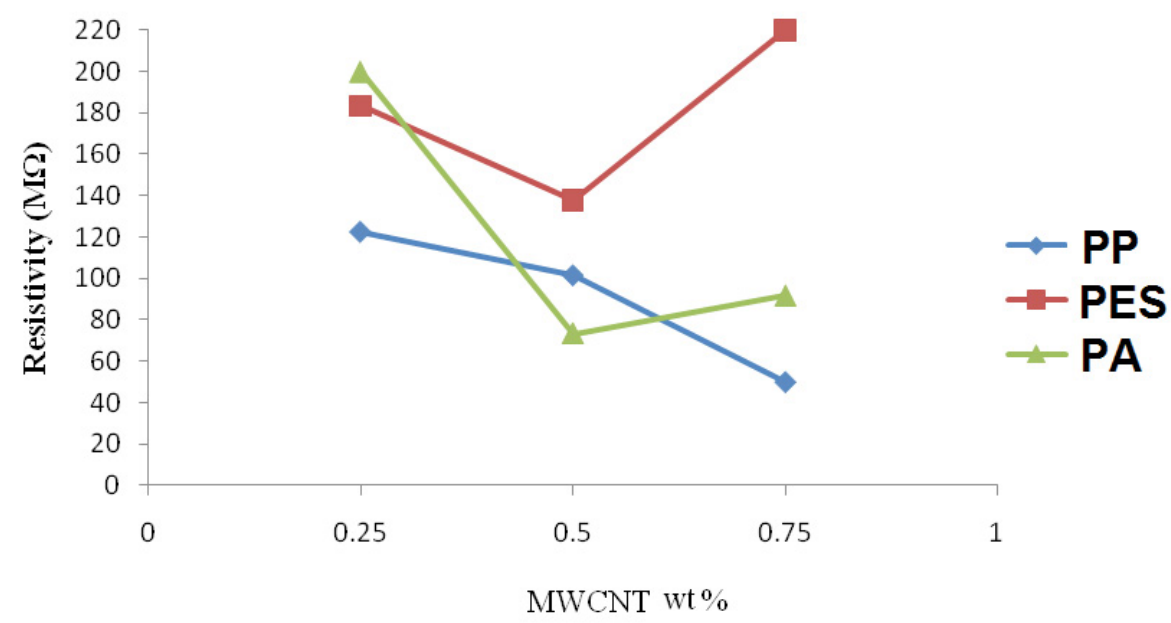

Figure 1. Influence of amount MWCNTs on surface resistance of fibres
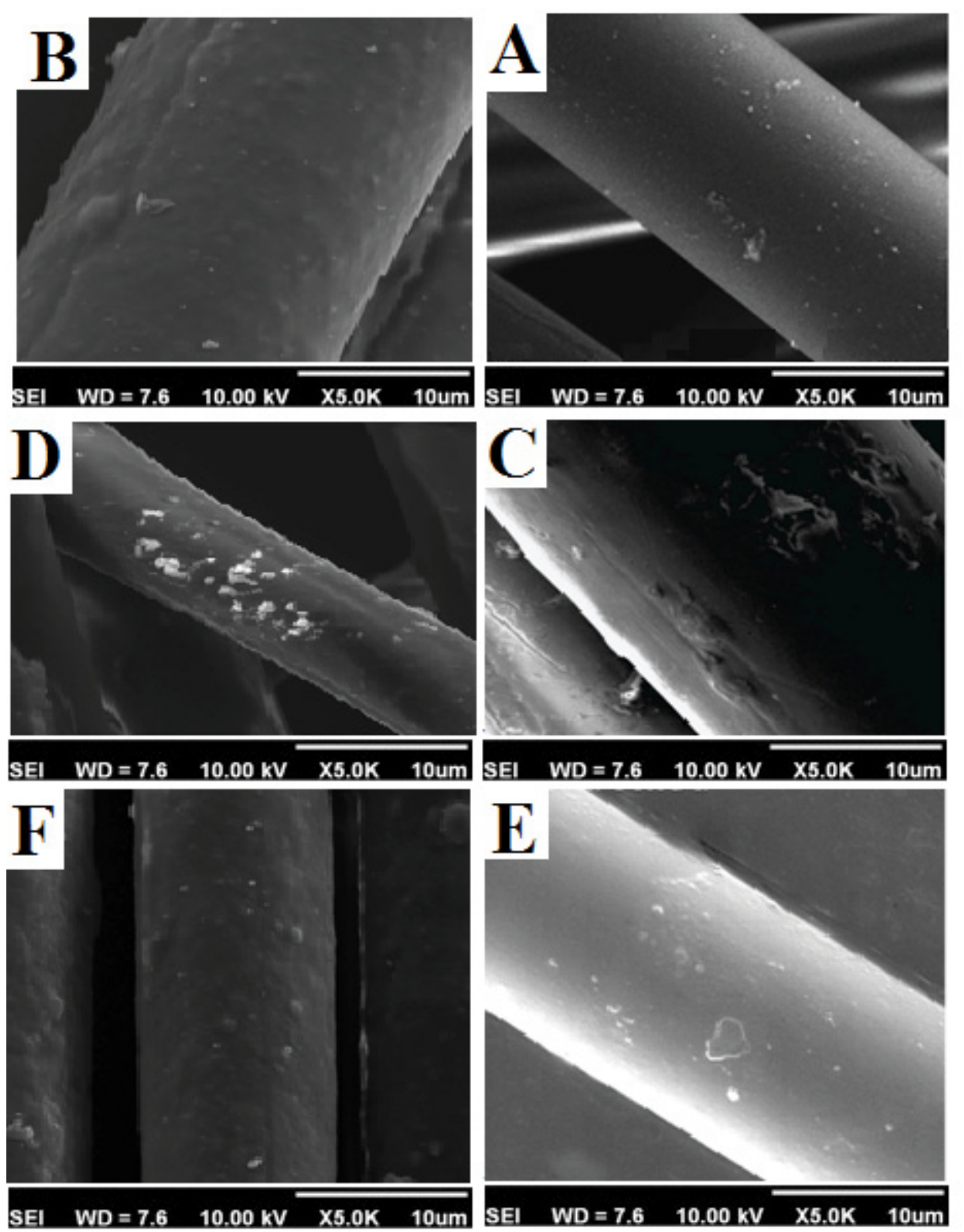

Figure 2. SEM images of samples, A) blank PA, B) PA with 0.5 wt $\%$ CNTs, C) blank PES, D) PES with 0.5 wt $\%$ CNTs, E) blank PP and F) PP with $0.5 \mathrm{wt} \%$ CNTs 

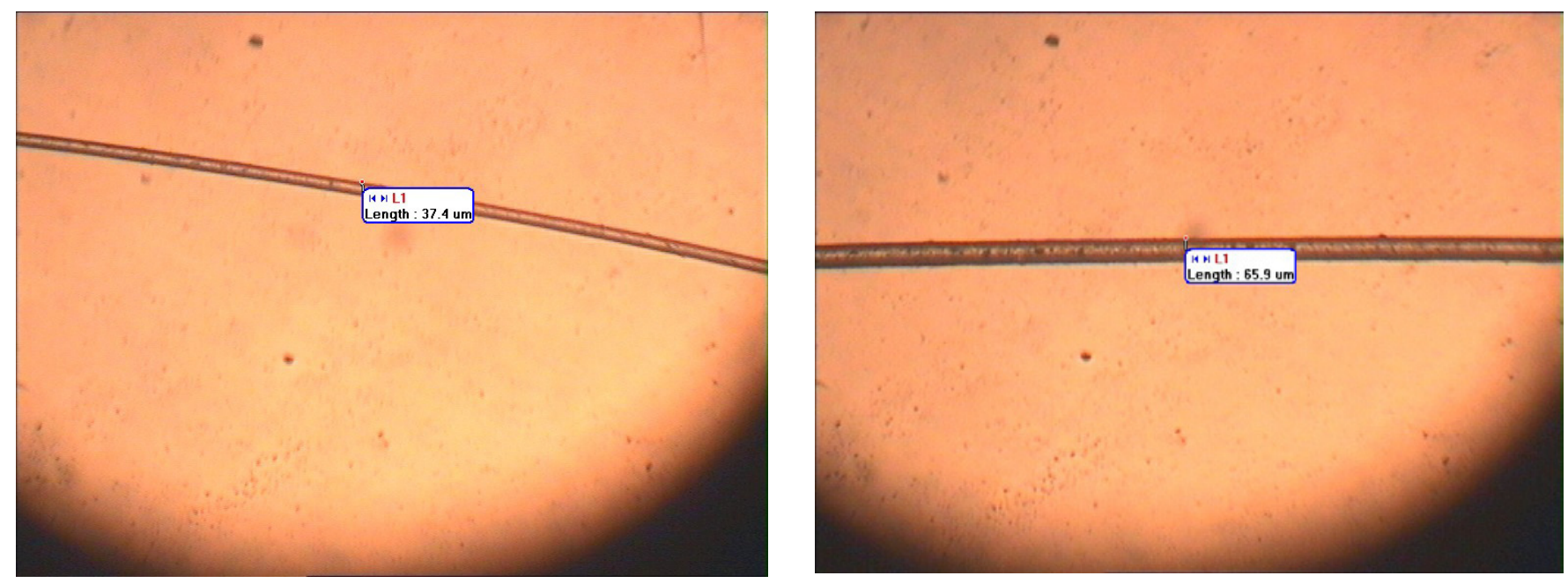

Figure 3. The stereoscope images of the melt spun conductive fibres

Table 3. Effect of CNTs type on surface resistance of composite fibres.

\begin{tabular}{|c|c|c|}
\hline Polymer & $\begin{array}{l}\text { Rs of sample containing } 0.5 \text { wt\% MWCNTs } \\
\qquad(\mathrm{M} \Omega)\end{array}$ & $\begin{array}{l}\text { Rs of sample containing } 0.5 \mathrm{wt} \% \text { SWCNTs } \\
(\mathrm{M} \Omega)\end{array}$ \\
\hline PP composite fibre & 101.3 & 1.021 \\
\hline PES composite fibre & 137.5 & 0.805 \\
\hline PA composite fibre & 73.33 & 0.560 \\
\hline
\end{tabular}

Table 4. Thermal properties of the CNTs-polymeric composites.

\begin{tabular}{|c|c|c|c|c|}
\hline & $T_{\mathrm{c}}\left({ }^{\circ} \mathrm{C}\right)$ & $T_{\mathrm{m}}\left({ }^{\circ} \mathrm{C}\right)$ & $\Delta H(\mathbf{J} / \mathbf{g})$ & $\operatorname{Cry~(\% )~}$ \\
\hline $\mathrm{PP}$ & 82.11 & 166.99 & 71.25 & 30 \\
\hline $\mathrm{PP}+0.5 \mathrm{wt} \%$ MWCNTs & 92.40 & 166.15 & 89.82 & 37 \\
\hline $\mathrm{PP}+0.5 \mathrm{wt} \%$ SWCNTs & 85 & 167 & 91.5 & 38 \\
\hline $\mathrm{PA}$ & 55.54 & 224.7 & 47.2 & 59 \\
\hline $\mathrm{PA}+0.5 \mathrm{wt} \%$ MWCNTs & 60 & 225.61 & 50.43 & 64 \\
\hline $\mathrm{PA}+0.5 \mathrm{wt} \%$ SWCNTs & 50.9 & 224.73 & 50.22 & 65 \\
\hline PES & 80.21 & 258 & 53.21 & 73 \\
\hline PES + 0.5 wt\% MWCNTs & 75 & 258.3 & 34.35 & 47 \\
\hline PES + 0.5 wt\% SWCNTs & 85.32 & 258.8 & 39.3 & 52 \\
\hline
\end{tabular}

diameter has been changed at different experiments due to the lack of gear pomp and control of winding speed of fibres.

\section{DSC analysis}

The variation of the DSC curves of PP, PES and PA fibres is given in Figure 4. The results of DSC analysis are shown in Table 4. The DSC curves indicate that the melting temperature of PP, PES and PA in this study is around $166.99^{\circ} \mathrm{C}, 224.7^{\circ} \mathrm{C}$ and $258^{\circ} \mathrm{C}$, respectively. By adding CNTs to polymers matrix, their melting temperature, crystallization temperature and degree of crystalline was slightly increased. The addition of CNTs into pure PP, PES and PA fibres results in a further increase of the enthalpy. The addition of CNTs in a polymer matrix accelerates the nucleation and crystal growth of the polymer. Crystal nucleation occurs at the surface of the CNTs in such a way that each nanotube becomes coated with a uniform layer of crystalline polymer.

\section{Mechanical properties of fibre bundle}

The mechanical strength of the melt spun fibres was investigated using a tearing tester machine (INSTRON 3365) on the bundle of fibres. The results from mechanical test on melt spun blank fibre and CNTs-polymers composite are presented in Table 5 . The strength of CNTs-PA fibre bundle 

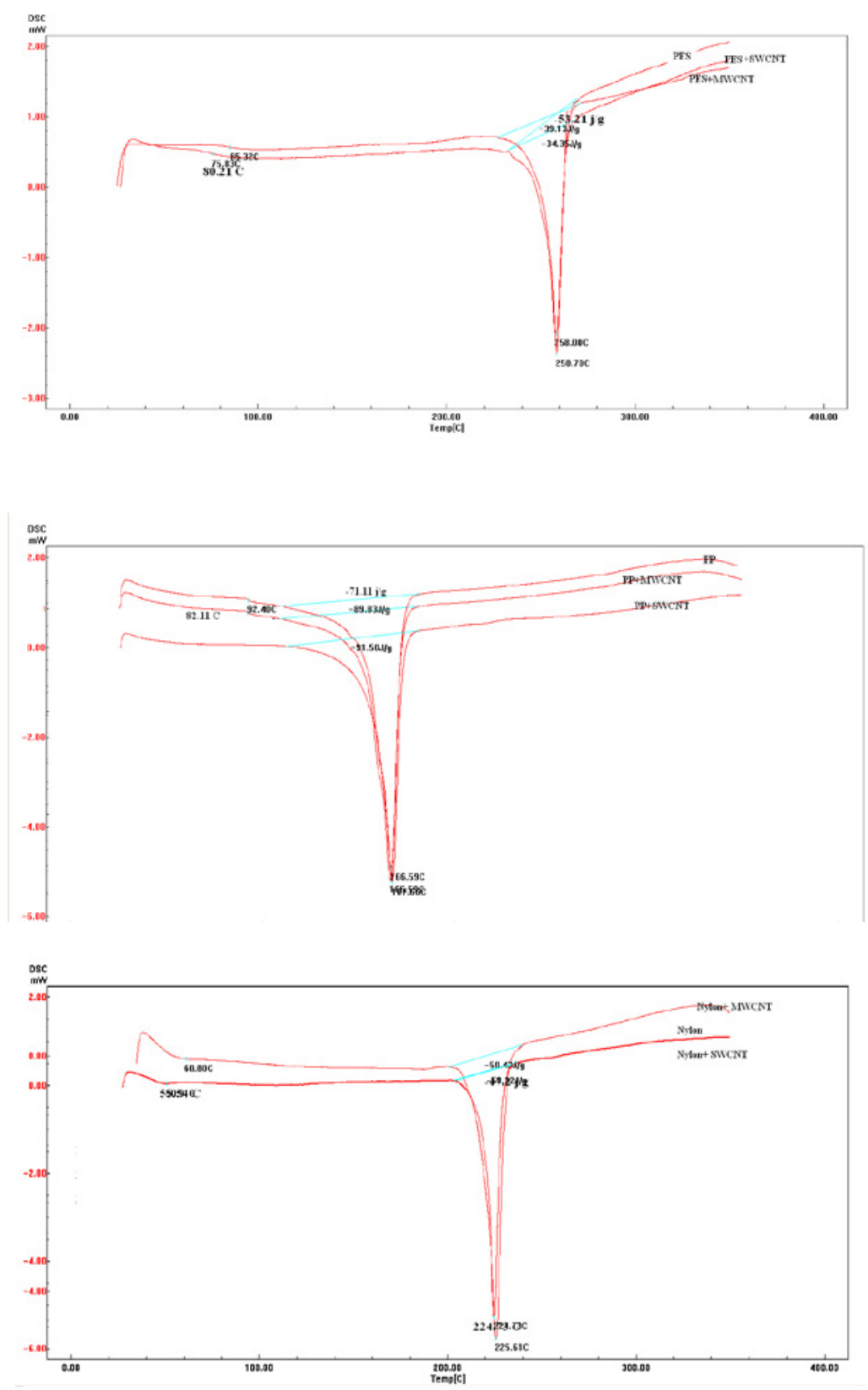

Figure 4. DSC curves of A) PES, B) PP, and C) PA composite fibres

was higher when compared with other samples, and the lowest strength was shown in PP fibres. Also, reinforcement effect of the SWCNTs was higher than MWCNTs. In addition, more elongation appeared by adding SWCNTs in comparison with MWCNTs.

\section{Conclusion}

This research presented a novel and efficient method for creating conductive fine fibres using CNTs. The results show that adding CNTs to polymer matrix had tangible effect on its conductivity and by increasing the amount of CNTs, the electrical conductivity increased. Also, the type of polymers studied indicate that the melt spun PA fibre has the highest conductivity due to better melt spinning capability and uniform
Table 5. Mechanical properties of the fibre bundles.

\begin{tabular}{|c|c|c|}
\hline Sample & $\begin{array}{c}\text { Tensile } \\
\text { strength } \mathbf{( N )}\end{array}$ & $\begin{array}{c}\text { Elongation } \\
\mathbf{( m m )}\end{array}$ \\
\hline $\mathrm{PA}$ & 0.15 & 41.4 \\
\hline $\mathrm{PA}+0.5 \mathrm{wt} \% \mathrm{MWCNTs}$ & 0.201 & 53.97 \\
\hline $\mathrm{PA}+0.5 \mathrm{wt} \%$ SWCNTs & 0.318 & 59.11 \\
\hline $\mathrm{PP}$ & 0.05 & 54.21 \\
\hline $\mathrm{PP}+0.5 w t \%$ MWCNTs & 0.083 & 73.41 \\
\hline $\mathrm{PP}+0.5 w t \%$ SWCNTs & 0.281 & 117.09 \\
\hline $\mathrm{PES}$ & 0.09 & 53.4 \\
\hline PES + 0.5 wt $\%$ MWCNTs & 0.132 & 62.02 \\
\hline PES + 0.5 wt $\%$ SWCNTs & 0.237 & 85.67 \\
\hline
\end{tabular}


distribution of CNTs into polymeric matrix. Moreover, the SWCNTs-polymer composite has lower surface resistance than MWCNTs-polymer composite. Melt spinning of CNTs-polymer composite results in better thermal properties and tensile strength of fibres. Also, reinforcement effect of the SWCNTs was higher than MWCNTs. With regard to the method applied in this research, mass production of this product is possible.

\section{References}

[1] Hu L., Pasta M., Mantia F.L., Cui L., Jeong S., Deshazer H.D., Choi J.W., Han S.M. and Cui Y., 2010, Stretchable, porous, and conductive energy textiles, Nano letters, vol. 10(2), pp. 708-714.

[2] Mai, H.J., Roth S., 1986, Elektrisch leitende kunstsoffe, Hanser Verlag: München Wien.

[3] Soroudi A. and Skrifvars M., 2010, Melt blending of carbon nanotubes/polyaniline/polypropylene compounds and their melt spinning to conductive fibres, Synthetic Metals, vol. 160, pp. 1143-1147.

[4] Pomfret S.J., Adams P.N., Comfort N.P. and Monkman A.P., 1999, Advances in processing routes for conductive polyaniline fibres, Synthetic metals, vol. 101(1), pp. 724725.

[5] Mirjalili M., Nateghi M.R., Mortezazadeh S. and Karimi L., 2013, Preparation of pyrrole-thiophene conductive polymeric composite on cotton fabric, Asian Journal of Chemistry, vol. 25 (12), pp. 6673-6678.

[6] Karimi L., Yazdanshenas M. E., Khajavi R., Rashidi A., and Mirjalili M., 2014, Using graphene/TiO nanocomposite as a new route for preparation of electroconductive, selfcleaning, antibacterial and antifungal cotton fabric without toxicity, Cellulose, vol. 21 (5), pp. 3813-3827.

[7] Huang J., Zhang Q., Zhao M., and Wei, F., 2012, A review of the large-scale production of carbon nanotubes: The practice of nanoscale process engineering, Chinese Science Bulletin, vol. 57(2-3), pp.157-166.

[8] Sun M., Feng J., Qiu H., Fan L., Li X., and Luo C., 2013, CNT-TiO2 coating bonded onto stainless steel wire as a novel solid-phase microextraction fiber, Talanta, vol. 114, pp. 60-65.

[9] Wei B. Q., Vajtai R., and Ajayan P. M., 2001, Reliability and current carrying capacity of carbon nanotubes, Applied Physics Letters, vol. 79(8), pp. 1172-1174.

[10] Dürkop T., Kim B. M., and Fuhrer M. S., 2004, Properties and applications of high-mobility semiconducting nanotubes, Journal of Physics: Condensed Matter, vol. 16(18), pp. 553-580.

[11] Singh B. P., Bharadwaj P., Choudhary V., and Mathur R. B., 2014, Enhanced microwave shielding and mechanical properties of multiwall carbon nanotubes anchored carbon fiber felt reinforced epoxy multiscale composites, Applied Nanoscience, vol. 4(4), pp. 421-428.
[12] AminiA., Zohoori S., MirjaliliA., Karimi L., and Davodiroknabadi A., 2014, Improvement in physical properties of paper fabric using multi-wall carbon nanotubes, Journal of Nanostructure in Chemistry, vol. 4(2), pp. 1-5.

[13] Pilehrood M. K., Heikkilä P., and Harlin A., 2012, Preparation of carbon nanotube embedded in polyacrylonitrile (pan) nanofibre composites by electrospinning process, AUTEX Research Journal, vol. 12(1), pp. 1-6.

[14] Mezghani K., Farooqui M., Furquan S., and Atieh M., 2011, Influence of carbon nanotube (CNT) on the mechanical properties of LLDPE/CNT nanocomposite fibers, Materials Letters, vol. 65(23), pp. 3633-3635.

[15] Kearns J.C. and Shambaugh R.L., 2002, Polypropylene fibers reinforced with carbon nanotubes, Journal of Applied Polymer Science, vol. 86(8), pp. 2079-2084.

[16] Haggenmueller R., Gommans H.H., Rinzler A.G., Fisher J.E. and Winey K.I., Aligned single-wall carbon nanotubes in composites by melt processing methods, Chem. Phys. Lett., vol. 330(1-2), pp. 21-225.

[17] Potschke P., Bruning H., Janke A., FischerD. and Jehnichen D., 2005, Orientation of multiwalled carbon nanotubes in composites with polycarbonate by melt spinning, Polymer, vol. 46(23), pp. 10355-10363.

[18] Sennett M., Welsh E., Wright J.B., Li W.Z., Wen J.G. and Ren Z.F., 2003, Dispersion and alignment of carbon nanotubes in polycarbonate, Appl. Phys. A: Mater. Sci. Proc., vol. 76(1), pp. 111-113.

[19] Fornes T.D., Baur J.W., Sabba Y. and Thomas E.L., 2006, Morphology and properties of meltspun polycarbonate fibers containing single- and multi-wall carbon nanotubes, Polymer, vol. 47(5), pp.1704-1714.

[20] Siochi E.J., Working D.C, Park C., Lillehei P.T., Rouse J.H., Topping C.C., Bhattacharyya A.R. and Kumar S., 2004, Melt processing of SWCNT-polyimide nanocomposite fibers, Compos. Part B: Eng., vol. 35(5), pp.439-446.

[21] Sandler J.K.W., Pegel S., Cadek M., Gojy F., Van Es M., Lohmar J., Blau W.J., Schulte K., Windle A.H. and Shaffer M.S.P., 2004, A comparative study of melt spun polyamide-12 fibres reinforced with carbon nanotubes and nanofibres, Polymer, vol. 45(6), pp. 2001-2015.

[22] Li Z., Luo G., Wei F., Hunag Y., 2006, Microstructure of carbon nanotubes/PET conductive composites fibers and their properties, Compos. Sci. Technol., vol. 66(7-8), pp. 1022-1029.

[23] Chen W., Tai X. and Liu Y., 2006, Carbon nanotubereinforced polyurethane composite fibers, Compos. Sci. Technol., vol. 66(15), pp. 3029-3034.

[24]Meng Q. and Hu J., 2008, Self-organizing alignment of carbon nanotube in shape memory segmented fiber prepared by in situ polymerization and melt spinning, Compos. Part A: Appl. Sci. Manuf, vol. 39(2), pp.314-321.

[25] Morton W.E., Hearl J.W.S., 1975, Physical Properties of Textile Fibers. 2th Ed., The Textile Institute, Manchester. 